\section{La lucha por la} patria atraviesa fronteras:

\section{pasquines}

sediciosos y

difusión de ideas

revolucionarias

en Cerro de Pasco,

Perú (1812)

\section{Marisa Davio[*]}

[*] Instituto Superior de Estudios Sociales (ISES) CONICET — San Miguel de Tucumán — Argentina. E-mail:mari.davio@gmail.com

ORCID: https://orcid.org/0000-0002-2942-1680
Resumen: Dentro del contexto de la guerra en el Alto Perú y la difusión de los ideales revolucionarios en los diferentes ámbitos pertenecientes al espacio rioplatense y del aún vigente virreinato del Perú, la intención de este trabajo se basa en el análisis, a partir de un caso judicial particular, del contexto de la guerra generado entre realistas y revolucionarios por la recuperación del territorio altoperuano y la lucha a favor o en contra de la continuidad del orden colonial en América.

Palabras clave: Pasquines; Revolucionarios; Rumores.

A luta pela pátria atravessa fronteiras: pasquins sediciosos e difusão de ideias revolucionárias em Cerro de Pasco, Peru (1812)

Resumo: No âmbito da guerra no Alto Peru e da difusão de ideais revolucionários nas diferentes regiões pertencentes à área do rio da prata e ao vice-reinado ainda prevalecente do Peru, a intenção deste trabalho é analisar, com base num processo judicial em particular, o contexto da guerra gerada entre realistas e revolucionários pela recuperação do território do Alto Peru e pela luta a favor ou contra a continuidade da ordem colonial na América.

Palavras-chave: Pasquins; Revolucionários; Rumores. 


\section{Introducción}

$\mathrm{E}$ 1 trabajo analiza un caso judicial particular, inmerso en una guerra entre dos proyectos políticos — realistas y revolucionarios - que se disputaron la hegemonía en el territorio americano, ante la crisis de la monarquía hispánica y el surgimiento de los movimientos insurgentes. Es decir, se halla dentro de un conflicto fundado no sólo en el dominio de hombres reclutados, recursos y armas necesarios para lograr la victoria, sino fundamentalmente en una guerra en la que ambos bandos compitieron por medio de exhortaciones y difusión de sus ideales y promesas, la opinión a favor de su propia causa

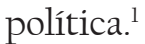

El caso judicial analizado relata el proceso seguido en 1812 a tres individuos oriundos de Cerro de Pasco, jurisdicción situada en las inmediaciones de Huánuco, en Perú, acusados y hechos prisioneros por difundir pasquines acordes con los ideales revolucionarios de la primera expedición al Alto Perú, dirigida por Juan José Castelli.

La metodología a utilizar se basa en el análisis de un expediente judicial, en función de los aportes teóricos e historiográficos de la historia político-conceptual de la primera mitad del siglo XIX. Dicho documento se complementa con información inédita relativa a la guerra en el Alto Perú y sus espacios aledaños, en base a las investigaciones que he venido realizando relativas a la cuestión y los aportes historiográficos claves relacionados con la participación de amplios sectores sociales en el proceso de militarización generado a partir de la guerra revolucionaria en América del Sur y la constante incertidumbre política ocasionada tras la crisis monárquica de 1808 y sus consecuencias en América.

En cuanto a los aportes teóricos, ha sido útil la categoría de análisis amigo/enemigo necesaria a la construcción de un "nosotros" (Parra, 2011) a la hora de profundizar en este expediente judicial contextualizado en una guerra entre proyectos políticos que se disputaron la hegemonía en el espacio sudamericano. ${ }^{2}$ Si bien en sus discursos aparecen éstos actores como enemigos irreconciliables, compartieron las mismas formas de convocatoria e intentaron reclutar e identificar a la misma población, necesaria para lograr un triunfo definitivo.

\footnotetext{
El trabajo forma parte de un proyecto de investigación de mayor alcance, basado en el análisis de perspectivas y experiencias de actores representantes de los bandos realista y revolucionario durante la guerra en el Alto Perú (18091819). Estrategias discursivas y conceptos políticos empleados en las cartas, notificaciones efectuadas entre jefes y oficiales, como asimismo arengas y proclamas dirigidas a las tropas de ambos bandos, se habrían constituido en esenciales para lograr convencimiento e identificación con la causa política a defender. Ante la escasez de municiones y armamentos para abastecer al Ejército, las palabras difundidas entre la oficialidad y las tropas se habrían convertido en el ala complementaria de las armas, en la base fundamental desde donde sostener la causa política.

${ }^{2}$ La propuesta teórica de Chantal Mouffe, a diferencia del enfoque del antagonismo, postula un modelo agonista, desarrollando la categoría de adversario. El agonismo sostiene la viabilidad de una relación nosotros/ellos en la que las partes en conflicto reconocen la legitimidad de sus oponentes. Al interior del "nosotros" que constituye la comunidad política, no se debe ver al adversario como enemigo a eliminar, sino como un oponente de legítima existencia. Sin embargo, la categoría de enemigo no desaparece -sigue siendo pertinente y se aplicará a aquéllos que cuestionen las bases mismas del orden democrático (Mouffe, 2007, p. 16-27).
} 
Por otro lado, el concepto de sociabilidad también resultó operativo a la hora de analizar las formas de difusión y comunicación de los ideales pertenecientes a ambos proyectos políticos en pugna, en un clima de amplias transformaciones. ${ }^{3}$

Los nuevos planteamientos historiográficos de las últimas décadas han procurado repensar el proceso, partiendo de la repercusión que tuvo para los coetáneos la crisis política de la Monarquía hispánica en 1808, la necesidad de legitimación de las nuevas instituciones creadas en representación de la soberanía real ausente y la concepción de las guerras revolucionarias como resultantes de una generalizada guerra civil desatada en casi todo el continente hispanoamericano (Fradkin, 2010).

Muchos autores han sostenido que, al no existir un Ejército nacional unificado, los bandos tanto revolucionarios como realistas debieron ganarse la adhesión de gente para hacer la guerra contra el enemigo (Thibaud, 2003 y 2007). No obstante, en muchas ocasiones, las interpretaciones de los actores se han visto obstaculizadas a causa de estudios nacionales que impidieron dimensionar la visión de los protagonistas desde la óptica y el espacio por el que circulaban.

La historiografía argentina ha intentado destacar la participación política de múltiples actores que contribuyeron monetaria o materialmente, del mismo modo que con hombres, para la guerra. En este sentido, existen estudios que señalan cómo los sectores populares, en su mayoría miembros de las tropas, idearon una serie de tácticas y resistencias para expresar sus desavenencias y resistencias, como la petición de derechos y concesiones por su participación militar (Di Meglio, 2006; Fradkin, 2008; López, 2002; Mata, 2007; Bragoni y Mata, 2007; Montero, 2008; Davio, 2010; Rabinovich, 2013; Fradkin y Di Meglio, 2013, entre otros)

Dentro del espacio sur-andino, recientes trabajos historiográficos contribuyeron a complejizar el estudio de la guerra de independencia en Charcas o el Alto Perú, tanto desde la comprensión de la posición particular asumida en este espacio - frente a la fidelidad a la Corona planteada por el virreinato de Lima desde los sucesos de 1809 y el movimiento revolucionario surgido en Buenos Aires en 1810 - como por los diferentes grupos sociales participantes en la guerra, en base a las opciones políticas a seguir (Roca, 2007; Salinas, 2009; Soux, 2013 y 2015; Soria, 2010).

Para el caso de la guerra en el entonces virreinato del Perú, que constituye el espacio en el que ocurre el caso a analizar, en los últimos años también se han abordado recientes temáticas referidas a la política de las autoridades virreinales y jefes del Ejército realista

${ }^{3}$ Pilar González Bernaldo sostuvo que, a partir de la Revolución de Mayo, cafés y tertulias aparecieron como las nuevas formas de sociabilidad política del espacio rioplatense, aunque limitadas a un reducido grupo de las élites e incluso dentro de la dirigencia revolucionaria. No obstante, ello no implicó que los sectores populares quedaran ajenos a la politización, surgida por medio de otros canales, como la acción guerrera o canales más informales (Bernaldo, 1991 y 2004; Guerra, 1995; Martínez, 2010, p. 25-36). 
frente a la guerra (O'Phelan, 2013), los conflictos surgidos en el seno de este que provocarían su desenlace a favor de los revolucionarios (Mazzeo, 2000, 2005 y 2009), las similitudes entre las estrategias y recursos adoptados entre estos y los jefes del bando revolucionario (Sobrevilla y Ortemberg, 2010 y 2012) o la reivindicación de los realistas en el contexto de la Revolución (Méndez, 1991 y 2005; Etcheverry, 2009.

En líneas generales, puede afirmarse que, en todos los territorios pertenecientes al virreinato del Perú ${ }^{4}$ y al rioplatense, ha comenzado a plantearse un renovado interés por el estudio de múltiples procesos, perspectivas, actores e imaginarios que hasta hace algunos años habían sido marginados o estudiados como procesos secundarios dentro de la historia político-institucional y de las grandes estructuras socioeconómicas. Si bien aún quedan caminos por recorrer y analizar experiencias, expectativas, marchas y contramarchas que generaron los procesos políticos y sociales sucedidos a raíz de la crisis monárquica y los procesos revolucionarios que le subsiguieron, estos nuevos abordajes aportan nuevas preguntas y complejizan, con sus aportes regionales y locales, el panorama de la historia general.

\section{Autos contra Mariano Cárdenas y Manuel Rivera}

El caso judicial a analizar ${ }^{5}$ constituye un buen ejemplo sobre la situación crítica experimentada por los revolucionarios en su tarea de difundir las noticias sucedidas a raíz de los movimientos juntistas en territorio americano y la lucha por lograr convencimiento e identificación con la causa a defender. Asimismo, los actores representantes del otro bando, los defensores de la causa del Rey, se ingeniaron para contrarrestar la propagación de la causa patriótica, como comenzó a catalogarse a los revolucionarios a partir de esta etapa, sobre todo a los provenientes del Río de la Plata. ${ }^{6}$

A su vez, creemos que este expediente ilustra muy bien el panorama de incertidumbre vivido por los actores en esos años conflictivos de lucha y cambios políticos constantes, que también se traslucen en el ámbito jurídico-institucional, como viene sosteniendo la

\footnotetext{
${ }^{4}$ Además de los ya citados, podemos mencionar algunos trabajos y compilaciones que dan cuenta de éstas nuevas perspectivas historiográficas: O'Phelan, 2001; McEvoy, Novoa y Palti, 2012; McEvoy y Stuven, 2007; O'Phelan, 2014; Contreras, 2015 etc.

${ }^{5}$ Se encuentra en el Archivo General de la Nación de Lima (AGN), Fondo Colonial. Real Audiencia, causas criminales, 1812.

${ }^{6}$ De acuerdo con David Velázquez Silva, en el virreinato del Perú, el término "patria” seguía utilizándose como lugar de origen y nacimiento, si bien iría adquiriendo cierta abstracción que aludía a su paulatina asociación con la causa revolucionaria (2014).
} 
historiografía de los últimos años. ${ }^{7}$ Veamos cómo fue elaborado, en qué contexto político aparece la denuncia a los reos, quiénes son los actores implicados y los funcionarios que intervienen en la resolución del caso, el cual tuvo su inicio en febrero de 1812, cuando se estaba produciendo una sublevación de indígenas y criollos en Huánuco que pregonaba la libertad de los americanos, basándose en las promesas difundidas por uno de los representantes de la revolución porteña, Juan José Castelli.

La causa analizada se desarrolla en el mismo momento en que surge dicha rebelión, en la que las proclamas y las exhortaciones pregonadas por Castelli, llegaron a difundirse en el Perú, motivando a los indígenas de Huánuco a movilizarse y planear una rebelión con la esperanza de que el rey Castel les daría apoyo (Hunefeldt, 1978, p. 33-58).

En los últimos años se ha debatido ampliamente, dentro de la historiografía, sobre la naturaleza de este movimiento (Espinosa, 2011, p. 181-212), llegando a cuestionar su identificación directa con el movimiento porteño y relacionarlo más bien con la multiplicidad de doctrinas anticoloniales que venían desarrollándose desde fines del siglo XVIII, como producto del descontento por las políticas abusivas de las autoridades españolas en América en el cobro de impuestos, la explotación en las actividades económicas fundamentales y la distribución y el trabajo de la tierra. ${ }^{8}$

A comienzos de febrero de 1812, el subdelegado de Cerro de Pasco, Mariano Ulloa, inició las declaraciones a los reos implicados, de acuerdo con las acusaciones efectuadas por un padre franciscano a los reos, por considerarlos revolucionarios, sediciosos, y por botar pasquines en las inmediaciones de las ciudades de Huánuco y Yauricocha. Además, se les acusaba de haber mantenido correspondencia con los rebeldes, sobre todo con los líderes porteños de la primera expedición al Alto Perú y los de Quito.

A tal efecto, Ulloa mandó comparecer a uno de los reos, Mariano Cárdenas, quien declaró ser vecino de la localidad, inocente y no conocer la causa de su prisión. Sólo admitió que el día del Corpus había cantado en la casa de otro vecino, llamado Manuel Rivera, unos versos patrióticos de la Concordia. ${ }^{9}$

\footnotetext{
${ }^{7}$ En las últimas décadas también se produjeron nuevos planteamientos historiográficos para analizar el tránsito de la colonia al período independiente y republicano y las diferentes justicias que actuaban y se superponían en la resolución de los casos judiciales, dando como resultado, en muchas ocasiones, la posibilidad de que los agentes apelaran a estas instancias para resolver sus conflictos en el contexto crítico que les tocó vivir y que produjo transformaciones, pero, a la vez, superposiciones y solapamientos en las formas específicas del ejercicio del poder. Como algunos de los trabajos que dan cuenta de estos nuevos estudios de las justicias en el espacio rioplatense podemos citar: Fradkin, 2008; Barriera, 2010 y 2014; Polimene, 2011; Piazzi, 2011 etc.

8 Jean Piel interpretó que la rebelión de Huánuco representa más bien la lucha dentro de un largo ciclo de rebeliones anticoloniales andinas en el siglo XVIII. La rebelión de 1812, a la vez indígena y criolla, no es ajena a los acontecimientos porteños, pero sus actores, manifiestos y formas de lucha tienen una singularidad andina propia (Piel, 2010).

${ }^{9}$ Según lo que posteriormente se aclara en el juicio, dichos versos de la Concordia eran acordes a la causa del rey, la religión y la patria, por lo tanto no ofensivos.
} 
El subdelegado recusó dicha argumentación, pues si los versos cantados eran patrióticos, por qué se habían encontrado unos que decían "el chapetón y el criollo se unieron en amistad, con la misma intimidad que un gavilán con un pollo", situación que ponía en evidencia su posible relación con las ideas de los insurgentes y sus pretensiones de separarse de los intereses de España. A esta reconvención, Cárdenas reconoció que estos versos se los había proporcionado un padre mercedario de apellido Aspiazu, quien le había anoticiado la situación existente en Buenos Aires, Quito y Chile, como asimismo las noticias de haber muerto los cabezas revolucionarios que, según su versión, de seguir aún vivos, "habrían alcanzado el perdón concedido por el Consejo de Regencia, situado en España”.

Estas frases a las que se hacían alusión en la declaración deben comprenderse desde la rivalidad entablada entre criollos y españoles, las disputas sobre derechos políticos y económicos en los territorios americanos y la querella por el acceso a las tierras y pago de tributos por parte de las comunidades indígenas —es decir, dentro del contexto iniciado en las sublevaciones de 1780 en el Alto Perú, ${ }^{10}$ la crítica situación establecida con la crisis monárquica de 1808 y la proclamación de juntas en diferentes puntos de América desde 1810.

Además, las recientes insurrecciones ocurridas en Huánuco, Panataguas y también en suelo altoperuano dan cuenta de la compleja situación que debieron enfrentar los realistas al divulgarse los ideales de uno de los líderes de la primera expedición al Alto Perú, Juan José Castelli."

Las fuentes encontradas dan parte de este problema ${ }^{12}$ y de la sensación de cercamiento experimentada por los seguidores de la causa del Rey, ante la difusión progresiva de los ideales revolucionarios provenientes del Río de la Plata.

En tal sentido, el virrey Abascal, que comandó la política contrarrevolucionaria desde Lima, durante los años claves de 1806 a 1816, empleó una serie de estrategias para impedir que se difundan los ideales de los insurgentes. Es decir, los bandos y proclamas de virrey Abascal tendían a resaltar el espíritu de engaño y seducción, fomentado tanto por los responsables de los sucesos ocurridos en Chuquisaca y La Paz como por los revolucionarios de Buenos Aires, que habían llevado a la necesidad de anexar el territorio del Alto Perú a su jurisdicción, respondiendo al proprio pedido de los perjudicados (Davio, 2016, p.153). Asimismo, Abascal

\footnotetext{
${ }^{10}$ Estudios del área andina analizan las raíces del movimiento insurgente en las sublevaciones indígenas propiciadas por Tupac Amaru en Cuzco, Tupac Katari en La Paz y Tomás Katari en la región de Chayanta (actual norte de Potosí). Ellos advierten la colaboración de indígenas y criollos en pos de su autonomía y del pacto realizado con el Estado colonial, que postulaba la fidelidad al rey y el pago de tributos a la Corona, a cambio del ejercicio de cierto grado de autonomía en las comunidades indígenas (Serulnikov, 2006).

"Juan José Castelli, como representante de la junta, emitió proclamas ya en territorio altoperuano, teniendo en cuenta las características socioétnicas de la gran mayoría de los habitantes. Algunos trabajos han centrado su atención en la política de Castelli y otros representantes del bando revolucionario en el Alto Perú y su repercusión en distintos espacios aledaños (O'Phelan y Lomné, 2013, p. 271-301; Mazzeo, 2007; Soux, 2007; Davio, 2015 y 2017).

${ }^{12}$ Expediente seguido en Tarma, sobre medidas de prevención y defensa de la ciudad y proceso instaurado a los reos, en Temple, 1971, pp. 123-172, y AGN, Lima, Fondo Colonial. Institucional
} 
alertaba sobre cualquier indicio de reunión en tertulias, discusiones o debates para acusar rápidamente de intento de conspiración contra la causa del rey, de manera a cortar de raíz cualquier posible conato subversivo que se estuviera gestando. ${ }^{13}$

Volviendo a las declaraciones del juicio, continuó la del otro reo, Manuel Rivera, quien expresó ser natural de Quito, de edad 40 años, vecino de la localidad de Cerro de Pasco y de oficio platero. Ante las preguntas efectuadas, respondió que eran falsas todas las acusaciones. Acto seguido, comenzó a intervenir José Mariano Tapia, abogado comisionado perteneciente a la Real Audiencia, en calidad de juez letrado. Él tomó nuevamente declaraciones a los dos reos, ante el pedido del subdelegado Ulloa. ${ }^{14}$

En esta oportunidad, Rivera reafirmaba no conocer la causa de su prisión, no ser ni revoltoso ni alzado - como se aseguraba en las acusaciones que se le habían leído-y que sólo había convidado a comer a su casa a cuatro amigos y a sus esposas, todos vecinos de Pasco, entre los cuales se hallaba Cárdenas. Dijo también que solamente habían cantado unos versos de la Concordia que Cárdenas trajera de Lima, pero que no se los acordaba, "debido a la chicha que había tomado".

Estudios sobre la temática del alcohol en las comunidades andinas han logrado dar cuenta del rol que ocupó este como agente de sociabilidad y medio de comunicación con el "otro", como también la posibilidad de expresar sus desavenencias con los grupos que detentaban el poder (Abercrombie,1993, p. 98-120). Asimismo, en ciertos casos, el vino - a diferencia de la chicha - indicaba cierto nivel de enriquecimiento entre sus consumidores (Saignes, 1993, p. 27-45), con lo que podemos intuir que los acusados, pese a contar con su condición de vecindad, podrían haber pertenecido a un nivel social más bajo dentro de la escala social, además de permitirles su consumo la expresión de sus conocimientos políticos en torno a la guerra y la Revolución desarrollada en espacios más lejanos que el local.

En el juicio, se le preguntó a Rivera si había tenido conversaciones secretas con el padre Aspiazu. Él contestó que sí, que este había afirmado que venía el insurgente Castelli a defender a los criollos, que los europeos querían solamente gozar de los empleos, y también había hablado de noticias funestas de Quito.

Ante las presiones del subdelegado y del abogado Tapia, Rivera comenzó a admitir algunas de las acusaciones efectuadas contra él y Cárdenas, así como a confesar que tenía en su poder veinte o treinta décimas que el padre le había remitido y entregado personalmente en Pasco, para que las copie y las difunda en iglesias y calles, aunque él no las había llegado a difundir a través de pasquines.

${ }^{13}$ Los alzamientos que prendieron con alza, lo hicieron fuera de la capital -en Tacna, el 1811 y 1813; Huánuco, el 1812; y Cuzco, el 1814-, alejados del ojo visor del Virrey. No obstante, se encargó de reprimirlos sistemáticamente (O’Phelan, 2013, p. 122)

${ }^{14}$ Era usual que los subdelegados solicitaran un juez letrado para asistirlos en la resolución de los casos judiciales. 
Tapia también hizo comparecer a Cárdenas, quien reconoció que el padre le había dado esas décimas pero que él había quemado y creído que no eran de malicia o satíricas, al tratarse de un sacerdote. ${ }^{15}$

$\mathrm{Al}$ analizar las décimas que se adjuntan en el expediente, ${ }^{16}$ podemos reconocer algunos de los ideales acordes con la causa revolucionaria, como asimismo conceptos claves que circulaban en la época y sus resignificaciones a partir de la situación vivida en aquellos años. Es decir, los versos destinados a su enunciación y difusión hacían mención de la prisión del rey Fernando VII — ahora preso por Napoleón Bonaparte-, de los rumores sobre su supuesta muerte ${ }^{17}-\mathrm{y}$, por lo tanto, de su legítimo reemplazo por una autoridad americana en disconformidad con el Consejo de Regencia, que había asumido el depósito de la soberanía hasta el retorno del rey-, de las noticias sucedidas en España con los franceses y de la proliferación de movimientos juntistas en el Río de la Plata, Chile, Quito etc., que disputaban la obediencia a dicho consejo y la preparación de hombres, armas y recursos en diferentes espacios de América del Sur para el enfrentamiento con los Ejércitos realistas. Algunos fragmentos pueden ilustrar lo dicho anteriormente:

\author{
El español piensa en vano \\ Al público alucinar \\ Cada instante con hablar \\ Esas victorias ufano \\ Ya se descubrió el arcano \\ Que tanto nos ocultaron \\ Ya sabemos que ganaron \\ Toda España los franceses \\ Después que ya la maraña \\ De la Europa está sabida \\ ¿Deberá seguir unida \\ Nuestra América a la España? \\ [...] A una gloriosa acción \\ Se prepara el Tucumán \\ Y en Buenos Aires están en mayor fermentación
}

\footnotetext{
${ }^{15}$ Los otros tres vecinos que se hallaron en la reunión en la casa de Rivera también fueron llamados a declarar, pero negaron toda implicación en el caso y su relación con los reos.

${ }^{16}$ Según otras fuentes encontradas, estos versos también habían circulado en otros ámbitos y su difusión había sido objeto de acusaciones.

${ }^{17}$ Otros pasquines difundidos en el espacio rioplatense ya hacían mención al "regicidio" como fundamento para cuestionar la fidelidad de las colonias americanas a la Madre Patria (Mata, 2008, p. 188).
} 
Con una admirable unión

Están ya todos resueltos

A quedar primero muertos que dar su brazo a torcer.

[...] En Chile, ya se han movido

Y en el Perú Alto también

En el Cuzco, ay con un vaivén

Que ha de dar un estallido,

En Arequipa, oí un ruido

Que anuncia la conmoción

Y todos en conclusión

Para realizar sustento

Aguardan solo el momento

De una felizocasión

De acuerdo con los últimos versos transcriptos, es posible vislumbrar la manera en que se difundían noticias y rumores sobre la Revolución iniciada en Buenos Aires y en otros espacios, como también las campañas militares que se planeaban para enfrentar al enemigo. Así, la sociabilidad es clave para comprender la propagación de noticias políticas y la difusión de rumores respecto los acontecimientos sucedidos desde ambos bandos, en espacios y diferentes niveles sociales en los que circulaba la información (Bernaldo 1991).

En este sentido, llama la atención, por ejemplo, la alusión a la "gloriosa acción a prepararse en Tucumán", cuando la batalla que lograría resistir al avance realista ocurriría recién en septiembre de 1812, es decir, siete meses después de este acontecimiento. La historiografía tucumana transmitió la idea de que esta batalla habría sido estratégicamente pensada por el general Belgrano, en su decisión de no continuar hasta Córdoba, como las autoridades porteñas le ordenaban. Interpretaciones más recientes señalan que fue también el pueblo tucumano y la población perteneciente al actual noroeste argentino los que habrían sugerido a Belgrano prestar batalla en Tucumán para frenar el avance realista que avanzaba desde el Alto Perú (Saltor, 2003).

Por tanto, esta frase encontrada no solo reafirmaría esta hipótesis, sino que su presencia anticipada a los hechos estaría evidenciando la proliferación y la llegada masiva de noticias sucedidas en espacios más lejanos, pero que desde tiempos coloniales y, más aún, en este contexto de cambios mantenían íntima vinculación con los sucesos ocurridos en el espacio peruano, pese a constituirse éste en uno de los focos realistas más importantes de América del Sur. 
No obstante, también sería factible pensar la posibilidad de que la mencionada gloriosa acción hiciera referencia a la resistencia que preparaban los patriotas en todo el Tucumán — territorio más amplio, perteneciente a la Intendencia de Salta del Tucumán- frente a la guerra instaurada en el territorio altoperuano contra los realistas, ante la derrota sufrida en Huaqui en junio de 1811.

Las noticias sobre el acontecer político y militar eran conocidas por todos los sectores sociales, en diferentes ámbitos de sociabilidad. Los comentarios difundidos en lugares públicos - como calles o pulperías - los bandos militares y proclamas anunciados por los jefes o las noticias difundidas por los curas en las parroquias rurales constituyeron canales de información por los cuales se pudo acceder al conocimiento de los sucesos políticos y militares y asumir una posición al respecto. A esto se sumó la proliferación de rumores en diferentes espacios, que permitieron la difusión de noticias políticas y militares, sin el riesgo de ser descubiertas (Davio, 2011; Nanni, 2017).

En Huánuco y sus alrededores, pasquines, décimas y rumores difundidos dinamizaban el movimiento liderado por criollos, civiles y religiosos, permitiendo que la población local se informara sobre la situación política y los reclamos sucedidos en otros espacios, a fin de identificarse con ellos (Espinosa, 2011).

A pesar de los cambios producidos en el ámbito de sociabilidad de las élites en relación con la discusión de escritos y la aparición de espacios de opinión pública (Guerra y Lamperiere, 1995), el manuscrito y el rumor siguieron reinando en la esfera de la comunicación popular (Guerra, 2002).

Retornando al expediente, un decreto del Gobernador Intendente de Tarma exhortaba Tapia a comparecer nuevamente a Rivera. Este último volvió a admitir que guardaba esos versos ocultos, pero que solo uno era de su puño y letra - todos los demás pertenecían a Aspiazu y no le había difundido por ninguna parte.

Ante acusaciones e intimidaciones proferidas a los reos, entraron a escena otros funcionarios judiciales, a instancia de uno de los imputados, Mariano Cárdenas, ${ }^{18}$ quien apeló a un abogado defensor, José Gutiérrez, para resolver su caso. Él no sólo intentó dejar sin efecto la causa, al afirmar que las acusaciones no eran probatorias de la relación de los reos con los miembros de la insurgencia, sino que los funcionarios implicados en el caso, Ulloa y Tapia, no habían procedido correctamente, habiendo solicitado una suma de dinero a los reos para ponerlos en libertad.

\footnotetext{
${ }^{18}$ Cárdenas hizo saber que estaba preso con barra de grillos, manifestando su inocencia y culpabilizando su cautiverio
} a "Ios audaces calumniantes que abundan en estos lugares". 
Además, Gutiérrez afirmó que en la causa no había testigos ni denunciantes presentes, que su defendido "había actuado inocentemente cantando una copla que se consideró mal sonante en los días del Corpus", pero que esto no había producido efecto alguno contra la religión, el rey y la patria, y, por este motivo, solicitaba al Gobernador Intendente que se remitieran los autos originales en los que estaban los testimonios de las partes y que se revocaran estas providencias, encargándose nuevamente el Superior Tribunal. Afirmó que, atendiendo a las indulgencias concedidas por "las propias Cortes soberanas de la Nación" ante "crímenes más horribles y detestables", se concediera el perdón a estos reos y la libertad. ${ }^{19}$

De acuerdo con la petición del abogado defensor, el fiscal del crimen Eyzaguirre tomó parte en el asunto y reconoció que el subdelegado de $\operatorname{Pasco}^{20}$ y el abogado comisionado Tapia habían procedido abruptamente contra lo dispuesto por las leyes, formando cargos y reconvenciones sin las pruebas suficientes. Sin embargo, solicitaba tomar declaración al padre Aspiazu, que se hallaba prófugo. No obstante, Pareja, fiscal en lo civil, que también intervino las apelaciones del abogado defensor, resolvió que "el proceso convence las ideas revolucionarias de los reos, la detención y custodia secreta de los versos y papeles subversivos y su adhesión a las máximas", los cuales hablaban de romper la unión entre españoles y americanos. Por tal razón, pedía que aprehendiera al religioso Aspiazu y se llevara a los reos a las justicias respectivas.

A causa de las demoras en el caso, denunciadas por el reo Cárdenas, se sumaron otras acusaciones efectuadas por la mujer de este, Pascuala Bazán, quien denunciaba ahora al subdelegado al pretender pedirle dinero para poner a su marido en libertad. Como ella se había negado, intentó llevarla presa. Ella también recurrió a apelar al indulto de las Cortes para liberar a su marido.

\footnotetext{
${ }^{19}$ Las regiones que juraron fidelidad al Consejo de Regencia y luego a las Cortes constituidas en Cádiz en 1812 defendían la autonomía y la capacidad de decisión de los asuntos en América, como asimismo las leyes estipuladas en dicha carta, que permitían tener consideración en cuanto a los castigos dispuestos con anterioridad a su puesta en vigencia.

20 En cuanto a la actuación del subdelegado y las quejas que otros representantes de la justicia dejan traslucir en el caso, la historiografía ha venido señalando las críticas efectuadas por parte de las autoridades ya existentes a estos funcionarios que comienzan a tener mayor presencia en el escenario americano a partir de las reformas borbónicas. Estudios más recientes dan cuenta de cómo estos funcionarios borbónicos no sólo asumieron roles dentro de la justicia y la política del momento, entrando en contradicción en muchas ocasiones con otros actores, sino que también actuaron como verdaderos intermediarios entre las necesidades de las comunidades locales en América y la Corona de España, permitiendo un control más efectivo sobre los pueblos y un mejor manejo de las relaciones de poder en sus regiones a cargo. Además, a partir de la puesta en práctica de los principios establecidos en la Constitución de Cádiz, estos empleados reales llegaron a ocupar un papel importante en su aplicación y en la formación de los ayuntamientos constitucionales. Sobre los nuevos planteamientos que intentan enfocar en el estudio de estos funcionarios borbónicos y su rol como verdaderos mediadores de poder, véase: Terán, Marta y Gayol, 2010, p. 41-52; Guzmán, 2015, p. 1-36, entre otros estudios realizados por la Red de Estudios de las Subdelegaciones en América Borbónica. El Colegio de Michoacán, Michoacán, México.
} 
En virtud de esta carta de Pascuala, el abogado defensor volvió a intervenir, y finalmente el fiscal en lo civil decidió que se libre providencia al subdelegado Ulloa, por su exhortación a la mujer de Cárdenas. Se liberaron los presos -de acuerdo con el indulto concedido por las Cortes- pero así al padre Aspiazu, que continuaba prófugo. Esta resolución final la decidió el regente conde Esteripa Osma, en julio de 1812.

\section{Conclusión}

Según lo analizado en el trabajo, es posible reconocer las implicancias del caso en el ámbito político, es decir, dentro del contexto de guerra generado a partir de la difusión de ideales promulgados por los líderes revolucionarios en el Río de la Plata y el Alto Perú, frente a la política represiva del virrey Abascal y demás funcionarios realistas.

Como hemos podido observar, la causa judicial analizada tiene relación directa con la rebelión producida en Huánuco y los ideales difundidos por uno de los principales representantes de la junta porteña en este contexto, como lo fue Juan José Castelli. Esto puede comprobarse por medio de la mención a dicho representante en la causa, como también por la necesidad de difusión de los ideales patriotas en distintos ámbitos de sociabilidad, a fin de aunar fuerzas para derrotar a los defensores de la causa del rey.

Por otra parte, en el expediente puede observarse no solo la superposición de funciones y atribuciones asumidas por cada funcionario judicial, que provocó una dilatación del proceso y generó recelos entre los implicados, sino asimismo puede evidenciarse el grado de incertidumbre política ante la soberanía real ausente y la apelación a las leyes impartidas por las Cortes de Cádiz, que recién estaban implementándose y a las cuales el virreinato peruano se había adherido, de acuerdo con su fidelidad al Consejo de Regencia instalado en España. En este contexto incierto, no aparece una idea clara a qué recursos apelar para resolver el caso, dando lugar a una serie de ambigüedades y diferentes apelaciones para lograr una definitiva resolución y un alto grado de politización de los asuntos judiciales en esta época convulsionada.

La propagación de rumores, pasquines, noticias falsas y otros anuncios sobre los acontecimientos sucedidos a partir del proceso revolucionario iniciado en Buenos Aires y sobre las comunicaciones provenientes de España estuvieron presentes en los discursos de los actores y posibilitaron una visión más acabada del alto grado de información de los sucesos acontecidos en otros contextos, las noticias difundidas entre ambos virreinatos y la guerra entablada entre realistas y revolucionarios. ${ }^{21}$

\footnotetext{
${ }^{21}$ Sobre la guerra de información entablada entre ambos bandos, véase O 'Phelan y Lomné, 2013, p. 389-415.
} 
Consideramos que la sociabilidad promovida en diferentes espacios, entre los diversos actores sociales y las noticias difundidas por vías secretas o cartas enviadas por diferentes medios - por vías normales, por medio de espías y prisioneros fugitivos o la difusión de rumores y/o propagandas políticas-, resultaron cruciales para conocer los proyectos del bando enemigo e idear, de esta manera, alternativas de lucha, convencimiento e identificación con la causa perseguida por parte de la población involucrada, en un contexto de permanente construcción de sus propias propuestas políticas.

En este conflicto generado entre ambos proyectos políticos que se disputaban por medio de exhortaciones y promesas la opinión a favor de su propia causa política resultó esencial el convencimiento y el consenso de todos los actores pertenecientes a diferentes niveles sociales, para que, en palabras de Raúl Fradkin (2009), se lograra una "negociación de la obediencia" que permitiese una verdadera identificación con la causa a defender y se abriera paso a las múltiples redes de información y de recursos que aseguraran un triunfo definitorio no tan sólo en el espacio involucrado en este conflicto en particular, sino en todo el territorio donde estaba en juego el futuro de América del Sur. En este sentido, la resolución de cada litigio particular y la opinión a favor de la causa perseguida resultaban decisivas para la victoria de su propio proyecto político, como hemos podido observar con el caso judicial analizado. 


\section{Bibliografia}

ABERCROMBIE, Thomas. Caminos de la memoria en un cosmos colonizado: política de la bebida y la conciencia histórica en K'ulta. In: SAIGNES, Thierry (Ed.) Borrachera y memoria: la experiencia de lo sagrado en los Andes. Lima: Ifea, 1993, p. 98-120.

BARRIERA, Darío G. Justicias, jueces y culturas jurídicas en el siglo XIX rioplatense. Nuevo Mundo Mundos Nuevos. Disponible em: 〈http://nuevomundo. revues.org/59252>. Acesso em: 9 out. 2014.

La historia de las justicias y las otras historias. In: JORBA, Richard; BONAUDO, Marta (Cols.) Historia regional: enfoques y articulaciones para complejizar una historia nacional. Buenos Aires: Universidad Nacional de La Plata, 2014.

BERNALDO, Pilar González. La Revolución Francesa y la emergencia de nuevas prácticas de la política: la irrupción de la sociabilidad política en el Río de la Plata (1810-1815). Boletín del Instituto de Historia y Pensamiento Argentino Dr. Emilio Ravignani (Buenos Aires), n. 3, série 3, p. 7-27, 1. sem. 1991.

. La sociabilidad y la historia política. In: PANI, E.; Salmerón, A. (Coords.). Conceptuar lo que seve. FrançoisXavier Guerra, historiador: homenaje. Ciudad de México: Instituto Mora, 2004.

BRAGONI, Beatriz. Esclavos, libertos y soldados: La cultura política plebeya en Cuyo durante la revolución". In: FRADKIN, Raúl O. (Ed.). ¿Y el pueblo, dónde está? Contribuciones para una historia política popular de la Revolución de Independencia en el Río de la Plata. Buenos Aires: Prometeo Libros, p.107-150.

; MATA, Sara. Militarización e identidades políticas en la revolución rioplatense. Anuario de Estudios Americanos (Sevilha), v. 64, n. 1, p. 221-256, 2007.

CHASSIN, Jöelle. Guerra de información y guerra de propaganda entre Lima y Buenos Aires (1808-1812). In: O'PHELAN, S.; LOMNÉ, G. Abascal y la contraindependencia de América del Sur. Lima: Ifea, 2013, p. 389-415.

CONTRERAS, Carlos. El aprendizaje de la libertad: historia del Perú en el siglo de su Independencia. Lima: Fondo editorial, 2015.

; GLAVE, Luis Miguel (Eds.) La independencia en el Perú: iconcedida, concebida, conseguida? Lima: IEP, 2015
DAVIO, Marisa. Con la espada y la palabra: revolucionarios y realistas durante la guerra en Charcas (1809-1813). Tinkazos (La Paz), n. 38, v. 18, p. 109-126, 2015.

Construir la Revolución desde la opinión: proclamas, bandos y exhortaciones durante la guerra en el Alto Perú (1810-1814). Nuevo Mundo Mundos Nuevos. Disponível em: 〈http://nuevomundo.revues.org/71268〉. Acesso em: 10 out. 2017.

Entre Jujuy y Ayohuma: el general Manuel Belgrano al frente del Ejército Auxiliar del Perú (18121813). In: ORSI, Cristina Minutolo de et al. III Congreso Nacional Belgraniano siglo XXI. Buenos Aires: Instituto Nacional Belgraniano, 2015, p. 151-167.

La gran máquina de América del Sud se va precipitando hacia su ruina: percepciones y experiencias de los realistas durante la guerra en el Alto Perú. Investigaciones y Ensayos (Buenos Aires), v. 63, p. 143-170, jul.-dez. 2016.

Rumores, difamaciones y canales de comunicación de los sectores populares durante el proceso de militarización en Tucumán (1812-1854). Prohistoria (Rosário), 2011. Disponível em: 〈www. scielo.org.ar/scielo.php?script=sci_arttext\&epid=S185195042011000100003\&lng=es\&nrm=iso>. Acesso em: 12 out. 2012.

DAVIO, Marisa. Morir por la patria. Participación y militarización de los sectores populares em Tucumán. 18121854. Rosario. Prohistoria. 2018.

DI MEGLIO, Gabriel. iViva el bajo pueblo! La plebe urbana de Buenos Aires y la política entre la Revolución de Mayo y el rosismo. Buenos Aires: Prometeo Libros, 2006.

ESPINOSA, Claudio César. Borbones, liberales e ingas en Huánuco: siglo XVIII y XIX. Investigaciones Sociales (Lima), n. 27, v. 15, p.181-212, 2011.

ETCHEVERRY, Marcela. Los derechos de indios y esclavos realistas y la transformación política en Popayán, Nueva Granada (1808-1820), Revista de Indias (Madri), n. 246, v. 69, p. 45-72, 2009.

FRADKIN, Raúl O. (Org.). El poder y la vara: estudios sobre la justicia y la construcción del Estado en el Buenos Aires rural. Buenos Aires: Prometeo Libros, 2008. 
La conspiración de los sargentos: tensiones políticas y sociales en la frontera de Buenos Aires y Santa Fe en 1816. In: BRAGONI, Beatriz; MATA, Sara (Orgs.). Entre la Colonia y la República: insurgencias, rebeliones y cultura política en América del Sur. Rosario: Prohistoria, 2009.

. La revolución: guerra y orden social. In: GRUPO Los historiadores y el bicentenario. Dos siglos después: los caminos de la Revolución. Rosario: Prohistoria, 2010, p. 37-41.

. ¿Y el pueblo, dónde está? Contribuciones para una historia política popular de la Revolución de Independencia en el Río de la Plata. Buenos Aires: Prometeo Libros, 2008

DI MEGLIO, Gabriel (Orgs.) Hacer política: la participación popular en el siglo XIX rioplatense. Buenos Aires: Prometeo Libros, 2013.

GUERRA, François Xavier. Voces del pueblo: redes de comunicación y orígenes de la opinión en el mundo hispano (1808-1814). Revista de Indias, n. 225, v. 62, p. 357-384, 2002.

; LAMPIERIERE, Annick. Los espacios públicos en Iberoamérica: ambigüedades y problemas. Ciudad de México: FCE, 1995.

GUZMÁN, José Luis Alcauter. Subdelegados y ayuntamientos constitucionales: momentos gaditanos en Valladolid, 1812-1814, 1820-1822. In: SÁNCHEZ, Eduardo Alejandro Lópes; FERNÁNDEZ, José Luis Soberanes. La Constitución de Cádizen 1812 y su impacto en el Occidente novohispano. Ciudad de México: Universidad Nacional Autónoma de México, 2015, p. 1-36.

HENSEL, Sike. Mediadores de poder: actuación de los subdelegados y su significado para el dominio español en Nueva España (1787-1821). In: TERÁN, Marta; GAYOL, Víctor. La Corona rota: identidades y representaciones en las independencias iberoamericanas. Castellón: Universitat Jaume, 2010, p. 41-52.

HUNEFELDT, Christine. Los indios y la constitución de 1812. Allpanchis, n. 11-12, p. 33-58, 1978.

MARTÍNEZ, Oscar Guarín. La sociabilidad política: un juego de luces y sombras. Memoria Social (Bogotá), n. 14, v. 29, p. 25-36, jul.-dez. 2010.

MATA, Sara Emilia. Insurrección e independencia: la provincia de Salta y los Andes del Sur. In: FRADKIN, Raúl O. ¿Y el pueblo, dónde está? Contribuciones para una historia política popular de la Revolución de
Independencia en el Río de la Plata. Buenos Aires: 2008, p. 177-208.

La guerra de Independencia en Salta y la emergencia de nuevas relaciones de poder. Andes (Salta), n. 13, 2002.

Los gauchos de Güemes. Buenos Aires: Eudeba, 2007.

MCEVOY, Carmen; STUVEN, Ana María (Eds.). La República peregrina: hombres de armas y letras de América del Sur (1800-1884). Lima: Ifea-IEP, 2007.

MCEVOY, Carmen; NOVOA, Mauricio; PALTI, Elías (Eds.). En el nudo del Imperio: Independencia y democracia en el Perú. Lima: IEA-IEP, 2012.

MÉNDEZ, Cecilia. Los campesinos, la Independencia y la iniciación de la República. El caso de los Iquichanos realistas: Ayacucho (1815-1818). In: URBANO, Henrique; LAUER, Mirko (Eds.). Poder y violencia en los Andes. Cusco: CBC, 1991, p. 165-188.

The Plebeian Republic: The Huanta Rebellion and Themaking of the Peruvian State (1820-1850). Londres: Duke University Press, 2005.

MONTERO, Raquel Gil. La construcción de Argentina y Bolivia en los Andes meridionales. Buenos Aires: Prometeo Libros, 2008.

MOUFFE, Chantal. El retorno a lo político. Ciudad de México: FCE, 2007, p. 16-27.

NANNI, Facundo. Tras las huellas de George Lefebvre. Tucumán en las guerras de Independencia: rumores alarmistas, noticias falsas y temores compartidos. Nuevo Mundo Mundos Nuevos. Disponível em: 〈http:// nuevomundo.revues.org/71423>. Acesso em: 10 out. 2017. O'PHELAN, Scarlett (Org.). La independencia en el Perú: de los Borbones a Bolívar. Lima: PUCP, 2001.

La Independencia en los Andes: una historia conectada. Lima: Fondo Editorial, 2014.

; LOMNÉ, Georges. Abascal y la contra-independencia en América del Sur. Lima: Fondo Editorial, 2013.

ORTEMBERG, Pablo. Vírgenes generalas: acción guerrera y práctica religiosa en las campañas del Alto Perú y el Río de la Plata (1810-1818). Boletín del Instituto de Historia Argentina y Americana Dr. Emilio Ravignani (Buenos Aires), n. 35-36, 2. sem. 2011-1. sem. 2012, p. 11-42.

PARRA, María Concepción Delgado. El criterio amigo/ enemigo en Carl Schmitt: el concepto de lo político como una noción ubicua y desterritorializada. Cuadernos de Materiales, n. 23, p. 175-183, 2011. 
PAZ, Gustavo. Reordenando la campaña: la restauración del orden en Salta y Jujuy (1822-1825). In: FRADKIN, Raúl O. ¿Y el pueblo, dónde estấ Contribuciones para una historia política popular de la Revolución de Independencia en el Río de la Plata. Buenos Aires: 2008, p. 209-222.

PIAZZI, Carolina (Coord.) Modos de hacer justicia. Agentes, normas y prácticas: Buenos Aires, Tucumán y Santa Fe durante el siglo XIX. Rosario: Prohistoria, 2011. PIEL, Jean, Un improbable écho de la "Révolution de Mai" argentine: la rébellion de Huánuco en 1812. Nuevo Mundo Mundos Nuevos. Disponível em: 〈http:// nuevomundo.revues.org/58415〉. Acesso em: 27 set. 2017.

POLIMENE, María Paula (Org.). Autoridades y prácticas judiciales en el Antiguo Régimen: problemas jurisdiccionales en el Río de la Plata, Córdoba, Tucumán, Cuyo y Chile. Rosário: Prohistoria, 2011.

PRADA, Natalia Silva. Los Reinos de Indias y el lenguaje de la denuncia en el mundo atlántico (siglos XVII-XVIII). Dos años de aventuras históricas en un blog, en Create Space. Charleston: Amazon, 2014.

RABINOVICH, Alejandro. Ser soldado en las guerras de Independencia. Buenos Aires: Sudamericana, 2013.

ROCA, José Luis. Ni con Lima ni con Buenos Aires: la formación de un Estado Nacional en Charcas. Lima: Plural, 2007.

SALINAS, Julio Siles. Historia de la Independencia de Bolivia. La Paz: Plural, 2009.

SALTOR, Irene García de. La construcción del espacio político: Tucumán en la primera mitad del siglo XIX. Tucumán: Universidad Nacional de Tucumán, 2003.

SERULNIKOV, Sergio. Conflictos sociales e insurrección en el mundo colonial andino: el norte de Potosí en el siglo XVIII. Buenos Aires: FCE, 2006.

SILVA, Darío Velázquez. Patria: Perú. In: SEBASTIÁN, Javier Fernández (Ed.). Diccionario político y social del mundo iberoamericano: conceptos políticos fundamentales 1770-1880. Madri: Universidad del País Vasco, 2014.

SOBREVILLA, Natalia. Hermanos, compañeros y amigos de sus mismos contrarios: las guerras de Independencia en el sur andino (1805-1825). In: Dossier: las guerras frente a la crisis del orden colonial. Hispanoamérica, Buenos Aires, Programa Buenos Aires de historia política, 2010. Disponível em: 〈http://historiapolitica.com/datos/biblioteca/ sobrevilla.pdf $>$. Acessado em: 19 mar. 2013.
SOUX, María Luisa (Coord.). Bolivia, su historia. Tomo III. Reformas, rebeliones e Independencia (1700-1825). La Paz: Coordinadora de Historia, 2015.

Legalidad, legitimidad, lealtad: apuntes sobre la compleja posición política en Charcas (1808-1811) In. HEBRARD, Veronique; VERDÓ, Genevieve (Eds.). Las Independencias iberoamericanas: un objeto de la historia. Madri: Casa de Velásquez, 2013.

.Los discursos de Castelli y la sublevación indígena de 1810-1811. In: MCEVOY, Carmen; STUVEN, Ana María. La República peregrina: hombres de armas y letras en América Andina (1810-1884). Lima: Ifea-IEP, 2007.

TEMPLE, Ella Dumbar. Colección documental de la Independencia del Perú. Tomo III, v. 1. Conspiraciones y rebeliones en el siglo XIX. La rebelión de Huánuco, Panatahuas y Humalíes de 1812. Lima: Comisión Nacional del Sesquicentenario de la Independencia del Perú, 1971, p. 123-172.

THIBAUD, Clement. Definiendo el sujeto de la soberanía: repúblicas y guerra en la Nueva Granada y Venezuela (1808-1820). In: CHUST, Manuel; MARCHENA, Juan (Eds.). Las armas de la nación: Independencia y ciudadanía en Hispanoamérica (17501850). Veuvert: Iberoamericana, 2007.

Repúblicas en armas: los ejércitos bolivarianos en la guerra de Independencia en Colombia y Venezuela. Bogotá: Ifea-Planeta, 2003.

VIVÓ, Cristina Mazzeo de. El miedo a la revolución de Independencia en el Perú (1818-1824). In: ROSAS, Claudia (Ed.). El miedo en el Perú. Lima: PUCP, 2005, p. 167-182.

La fuerza de la palabra dicha: las proclamas de Juan José Castelli y su proyección continental. In: MCEVOY, Carmen; STUVEN, Ana María. La República peregrina: hombres de armas y letras de América del Sur (1800-1884). Lima: Ifea-IEP, 2007, p. 137-143.

Las vicisitudes de la guerra de Independencia en el Perú (1817-1824). Cuadernos de Investigación (Lima), n. 1, p. 105-136, 2000.

Los nudos de la desunión: conflictos y divergencias en la dirigencia del ejército realista durante la emancipación del Perú (1810-1824). Revista de Indias (Madri), n. 247, p. 105-135, 2009.

WASSERMAN, Fabio. Entre dos fuegos: la política de Castelli en el Alto Perú. In: O'PHELAN, Scarlett; LOMNÉ, Georges. Abascal y la contra-independencia de América del Sur. Lima: Ifea, 2013, p. 271-301. 